\title{
Sifat-Sifat Sistem Pendulum Terbalik dengan Lintasan Berbentuk Lingkaran
}

\author{
Nalsa Cintya Resti \\ Sistem Informasi Universitas Nusantara PGRI Kediri \\ Kediri, Indonesia \\ E-mail: nalsacintya@ unpkediri.ac.id
}

Abstrak - Pendulum terbalik adalah sistem non-linear orde tinggi, miltivariabel dan sistem dinamik yang sangat tidak stabil. Sistem non-linear orde tinggi pada pendulum terbalik harus dilinearisasi agar dapat diselesaikan dengan mudah. Dari perhitungan yang telah dilakukan dapat ditarik kesimpulan bahwa sistem dari pendulum terbalik adalah sistem yang tak stabil pelana, dapat dikontrol dan dapat diamati. Selain itu sistem juga dapat dibentuk menjadi sistem berbentuk kompanion terkontrol dan bentuk kompanion teramati.

Kata kunci-Sistem non-linear, pendulum terbalik, miltivariabel, sistem dinamik

\section{Pendahuluan}

Pendulum terbalik adalah sistem non-linear orde tinggi, miltivariabel dan sistem dinamik yang sangat tidak stabil. Pendulum pada jurnal ini adalah pendulum terbalik yang menggunakan lintasan berbentuk lingkaran. Lintasan berupa lingkaran bertujuan untuk menghilangkan batasan panjang lintasan yang terdapat pada pendulum terbalik dengan lintasan transversal. Pendulum terbalik adalah sistem sistem pendulum yang titik beratnya berada diatas titik tumpunya. Lintasan berupa lingkaran bertujuan untuk menghilangkan batasan lingkaran yang terjadi pada pendulum terbalik dengan lintasan lurus sehingga pendulum dapat disetimbangkan dengan leluasa. Pendulum terbalik adalah system yang tidak stabil. Secara umum, suatu pendulum selalu bergerak kembali ke posisi setimbangnya. Waktu yang diperlukan untuk mencapai posisi kesetimbangannya bergantung pada jarak antara titik tumpu dan titik beratnya.

\section{Metode Penelitian}

A. Model dari Pendulum Terbalik dengan Lintasan Lingkaran

Pendulum terbalik adalah sistem yang terdiri dari kontroler, lengan, pendulum, motor DC dan dua tongkat pendulum. Kontroler membuat pendulum tetap berada pada posisi tegak ke atas pada lengan pemutar. Adapun skema gambar dari Pendulum dapat dilihat pada gambar 1.

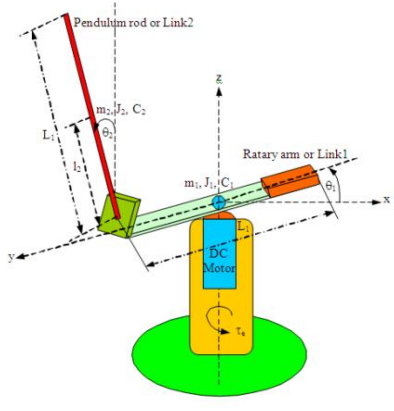


Jurnal INTENSIF, Vol.1, No.1, Februari 2017

ISSN: $2549-6824$

\section{GAMBAR I. SKEM A RIP DENGAN BEBERAPA PARAMETER}

Perpotongan antara lengan 1 dan lengan 2 tidak dapat digerakkan namun bebas berputar. Kedualengan memiliki panjang $L_{1}$ dan $L_{2}$ dan memiliki massa $m_{1}$ dan $m_{2}$ yang berlokasi pada $l_{1}$ dan $l_{2}$, yang merupakan panjang dari sudut rotasi lengan pusat massa.

\section{B. Model Fisika}

Gambar berikut adalah gambar skematik (free body diagram) dari pendulum terbalik beserta arah pergerakannya.

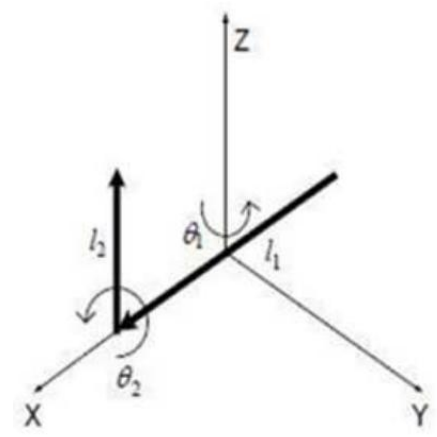

\section{GAMBAR II. SKEM ATIK PERGERAKAN PENDULUM TERBALIK}

Kecepatan angular dari masing-masing link adalah:

$$
\begin{gathered}
\bar{\omega}_{1}=\dot{\theta}_{1} \hat{k} \\
\bar{\omega}_{2}=-\dot{\theta}_{1} \cos \theta_{2} \hat{\imath}-\dot{\theta}_{1} \sin \theta_{2} \hat{\imath}+\theta_{2} k
\end{gathered}
$$

Kecepatan linear dari masing-masing link diberikan oleh:

$$
\begin{gathered}
\bar{v}_{1 e}=\dot{\theta}_{1} l_{1} \hat{\jmath} \\
\bar{v}_{2 c}=\theta_{1} L_{1} \sin \theta_{2} \hat{\imath}+\left(\dot{\theta}_{2} i_{2}+\dot{\theta}_{1} L_{1} \cos \theta_{2}\right) \hat{\jmath}-i_{2} \dot{\theta}_{1} \sin \theta_{2} \hat{k}
\end{gathered}
$$

Gaya listrik $E_{a}$ berbanding lurus dengan kecepatan rotor yang dinyatakan sbb:

$$
E_{a}=K_{v} \omega_{\tau}=K_{v} \dot{\vartheta}_{1}
$$

Torsi yang dihasilkan dinyatakan sbb:

$$
\tau_{e}=K_{\tau} i_{\alpha}=K_{V} i_{\alpha}
$$

Dengan $K_{v}$ adalah konstanta untuk tegangan dan $K_{\mathrm{\tau}}$ adalah konstanta untuk torsi. Dalam kondisi tunak (steady state), persamaan yang menggambarkan tegangan motor adalah:

$$
V_{a}=R_{a} i_{a}+E_{a}
$$

Sehingga

$$
i_{a}=\frac{V_{a}}{R_{a}}-\frac{E_{a}}{R_{a}}
$$

Dari substitusi persamaan didapatkan 
Jurnal INTENSIF, Vol.1, No.1, Februari 2017

ISSN: $2549-6824$

$$
\tau_{e}=\frac{K_{t} V_{a}}{R_{a}}-\frac{K_{t} K_{v} \theta_{1}}{R_{a}}
$$

Dimana $V_{\alpha}$ adalah tegangan yang diterapkan. Torsi diperlukan untuk lengan putar untuk mengubah arah rotasi dengan cepat untuk menjaga keseimbangan pendulum. Kecepatan tinggi pada pendulum diperlukan agar lengan dapat bergerak lebih cepat untuk mencegah jatuhnya pendulum.

\section{Model Matematika}

Dalam pengendalian optimal pendulum penurunan persamaan matematika yang menjelaskan dinamika dari sistem pendulum terbalik didasari oleh persamaan Euler-Lagrange:

$$
\frac{d}{d t}\left(\frac{\partial L}{\partial \dot{q}_{i}}\right)-\frac{\partial L}{\partial q_{i}}+\frac{\partial W}{\partial q_{i}}=Q
$$

Dimana:

$q_{i}=$ vektor posisi sudut (rad)

$\dot{q}=$ vektor kecepatan sudut $(\mathrm{rad} / \mathrm{s})$

$Q=$ gaya luar $(\mathrm{N})$

$L=$ Lagrangian $(\mathrm{J})$

$W=$ Energi yang hilang $(\mathrm{J})$

Dalam persamaan Euler-Lagrange, L didefinisikan sebagai:

$$
L(q, \dot{q})=E_{k_{\text {total }}}-E_{p_{\text {total }}}
$$

Dan

$$
q_{i}=\left[\theta_{1}, \theta_{2}\right]^{T}
$$

Energi kinetik dari link 1 adalah:

$$
E_{k_{\text {link } 1}}=\frac{1}{2}\left(\bar{v}_{1 c}^{T} m_{1} \bar{v}_{1 e}+\bar{\omega}_{1}^{T} \bar{l} \bar{\omega}_{1}\right)=\frac{1}{2} m_{1} i_{1}^{2} \dot{\theta}_{1}^{2}+\frac{1}{2} i_{1 z z} \dot{\theta}_{1}^{2}
$$

Karena pusat massa dari lengan seimbang pada awal, sedemikian hingga

$$
E_{k_{\text {link } 1}}=\frac{1}{2} i_{1} \dot{\theta}_{1}^{2}
$$

Energi kinetik dari link 2 dinyatakan dengan persamaan sebagai berikut:

$$
E_{k_{\text {link }}}=\frac{1}{2}\left(\bar{v}_{2 e}^{T} m_{2} \bar{v}_{2 e}+\bar{\omega}_{2}^{T} \bar{\iota}_{2} \bar{\omega}_{2}\right)
$$

$$
\begin{aligned}
& E_{k_{\operatorname{lin} k z}} \\
& =\frac{1}{2} \dot{\theta}_{1}^{2}\left(m_{2} L_{1}^{2}+\sin ^{2}\left(\theta_{2}\right)\right)\left(m_{2} i_{2}^{2}+i_{2 y y}\right)+\left(i_{2 x x} \cos ^{2}\left(\theta_{2}\right)\right)+\frac{1}{2} \theta_{1}^{2}\left(i_{2 z z}+m_{2} i_{2}^{2}\right) \\
& +m_{2} L_{1} i_{2} \dot{\theta}_{1} \dot{\theta}_{2} \cos \theta_{2}
\end{aligned}
$$

Energi potensial dari link 1 dan link 2 adalah:

$$
E_{p_{\text {Rin } k_{1}}}=0
$$




$$
E_{p_{\text {Rin } k: n}}=m_{2} g l_{2} \cos \theta_{2}
$$

Total Energi yang hilang dari sistem adalah jumlahan energi yang hilang dari tongkat pendulum (link 2) dan lengan (link 1), dinyatakan oleh persamaan berikut:

$$
W=\frac{1}{2} C_{1} \dot{\theta}_{1}^{2}+\frac{1}{2} C_{2} \dot{\theta}_{2}^{2}
$$

Dari persamaan (11), maka didapat Lagrangian:

$$
L=\frac{1}{2} i_{1} \dot{\theta}_{1}^{2}+\frac{1}{2} i_{2} \dot{\theta}_{2}^{2}+\frac{1}{2} m_{2}\left[\left(L_{1} \dot{\theta}_{1}+i_{2} \dot{\theta}_{2} \cos \theta_{2}\right)^{2}+\left(i_{2} \dot{\theta}_{2} \sin \theta_{2}\right)^{2}\right]-m_{2} g l_{2} \cos \theta_{2}
$$

Persamaan Euler-lagrange dari masing-masing variabel adalah:

$$
\begin{gathered}
\frac{d}{d t}\left(\frac{\partial L}{\partial \dot{\theta}_{1}}\right)-\frac{\partial L}{\partial \theta_{1}}+\frac{\partial W}{\partial \dot{\theta}_{1}}=\tau_{\theta} \\
\frac{d}{d t}\left(\frac{\partial L}{\partial \dot{\theta}_{2}}\right)-\frac{\partial L}{\partial \theta_{2}}+\frac{\partial W}{\partial \dot{\theta}_{2}}=0
\end{gathered}
$$

Dengan memasukkan persamaan sebelumnya kedalam persamaan Euler-Lagrange, akan menghasilkan persamaan non-linear dari dinamika RIP sebagai berikut:

$$
\begin{aligned}
& \left(i_{1}+m_{2} L_{1}^{2}\right) \ddot{\theta}_{1}+\left(m_{2} L_{1} i_{2} \cos \theta_{2}\right) \ddot{\theta}_{2}+\left(m_{2} L_{1} i_{2} \sin \theta_{2}\right) \dot{\theta}_{2}^{2}+C_{1} \dot{\theta}_{1}=\frac{K_{\mathrm{t}} V_{a}}{R_{a}}-\frac{K_{\mathrm{t}} K_{a} \theta_{1}}{R_{a}} \\
& \left(m_{2} L_{1} i_{2} \cos \theta_{2}\right) \ddot{\theta}_{2}+\left(i_{1}+m_{2} L_{1}^{2}\right) \ddot{\theta}_{1}+m_{2} g l_{2} \sin \theta_{2}+c_{2} \dot{\theta}_{2}=0
\end{aligned}
$$

D. Linearisasi Model

Untuk melinearkan model yang didapatkan, digunakan pendekatan sbb:

$$
\cos \theta \approx 1, \sin \theta \approx \theta, \dot{\theta}^{2} \approx 0
$$

Sehingga persamaan menjadi:

$$
\begin{aligned}
& h_{1} \ddot{\theta}_{1}+h_{2} \ddot{\theta}_{2}+C_{1} \dot{\theta}_{1}=h_{5} V_{a}-h_{6} \dot{\theta}_{1} \\
& h_{2} \ddot{\theta}_{1}+h_{3} \ddot{\theta}_{2}+h_{4} \theta_{2}+C_{2} \dot{\theta}_{2}=0
\end{aligned}
$$

Dimana didefinisikan:

$$
\begin{array}{lll}
h_{1}=i_{1}+m_{2} L_{1}^{2} & h_{2}=m_{2} L_{1} i_{2} & h_{3}=i_{2}+m_{2} L_{2}^{2} \\
h_{4}=m_{2} g i_{2} & h_{5}=\frac{K_{t}}{R_{a}} & h_{6}=\frac{K_{t} K_{v}}{R_{a}}
\end{array}
$$

Dengan eliminasi, diperoleh persamaan:

$$
\ddot{\theta}_{1}=\frac{-h_{g}\left(h_{6}+C_{1}\right) \theta_{1}-h_{2} h_{4} \theta_{2}+h_{2} C_{2} \theta_{2}+h_{g} h_{5} V_{a x}}{h_{1} h_{g}-h_{2}^{2}}
$$




$$
\ddot{\theta}_{2}=\frac{h_{2}\left(h_{6}+C_{1}\right) \theta_{1}+h_{1} h_{4} \theta_{2}+h_{1} C_{2} \theta_{2}+h_{28} h_{5} V_{a}}{h_{1} h_{8}-h_{2}^{2}}
$$

Maka persamaan (2-26), (2,27) sistem RIP dapat dinyatakan sebagai berikut:

$$
\begin{gathered}
\ddot{\theta}_{1}=-d_{1}\left(h_{6}+c_{1}\right) \dot{\theta}_{1}-d_{2} h_{4} \theta_{2}-d_{2} c_{2} \dot{\theta}_{2}+d_{1} h_{5} V_{a} \\
\ddot{\theta}_{2}=-d_{3}\left(h_{6}+c_{1}\right) \dot{\theta}_{1}-d_{4} h_{4} \theta_{2}-d_{2} c_{2} \dot{\theta}_{2}+d_{3} h_{5} V_{a}
\end{gathered}
$$

Adapun persamaan dapat dibentuk dalam sebuah matriks:

$$
\left[\begin{array}{l}
\dot{\theta}_{1} \\
\ddot{\theta}_{1} \\
\dot{\theta}_{2} \\
\ddot{\theta}_{2}
\end{array}\right]=\left[\begin{array}{cccc}
0 & 1 & 0 & 0 \\
0 & -d_{1}\left(h_{6}+C_{1}\right) & -d_{2} h_{4} & -d_{2} C_{2} \\
0 & 0 & 0 & 1 \\
0 & -d_{3}\left(h_{6}+C_{1}\right) & -d_{4} h_{4} & -d_{2} C_{2}
\end{array}\right]\left[\begin{array}{c}
\theta_{1} \\
\dot{\theta}_{1} \\
\theta_{2} \\
\dot{\theta}_{2}
\end{array}\right]+\left[\begin{array}{c}
0 \\
d_{1} h_{5} \\
0 \\
d_{3} h_{5}
\end{array}\right]
$$

Dengan $\theta$ merupakan simpangan maksimal dari link 1 dan link 2 sedangkan $\dot{\theta}$ merupakan kecepatan

\begin{tabular}{|c|c|c|c|}
\hline Parameter & Nilai & Parameter & Nilai \\
\hline$m_{1}(k g)$ & 0.830 & $\overline{J_{1}\left(\mathrm{kgm}^{-2}\right)}$ & 0.00208 \\
\hline$m_{2}(k g)$ & 0.100 & $I_{2}\left(\mathrm{kgm}^{-2}\right)$ & 0.001 \\
\hline$L_{1}(m)$ & 0.600 & $g\left(m s^{-2}\right)$ & 9.8100 \\
\hline$L_{1}(m)$ & 0.300 & $\boldsymbol{R} \alpha(\mathbf{\Omega})$ & 28.600 \\
\hline$C_{1}(N \cdot m \cdot s)$ & 0.000 & $\boldsymbol{k}_{v}(\boldsymbol{V} \boldsymbol{s})$ & 0.1680 \\
\hline$C_{2}(N . m . s)$ & 0.000 & $K t=K m\left(N \cdot m A^{-1}\right)$ & 1.680 \\
\hline$l_{1}(m)$ & 0.300 & $\tau_{e}(N-m)$ & 0.09810 \\
\hline$I_{e q}\left(k g m^{-2}\right)$ & 0.002 & $V_{a}(V)$ & 60.00 \\
\hline$L_{2}(m)$ & 0.100 & & \\
\hline
\end{tabular}
sudut dari msing-masing link.Adapun untuk nilai pada masing-masing parameter telah dilampirkan pada tabel 1 .

TABEL I. PARAMETER DARI SISTEM RIP

Sehingga dengan memasukkan nilai parameter ke dalam persamaan, didapatkan matriks berikut.

$$
\left[\begin{array}{l}
\dot{\theta}_{1} \\
\ddot{\theta}_{1} \\
\dot{\theta}_{2} \\
\ddot{\theta}_{2}
\end{array}\right]=\left[\begin{array}{cccc}
0 & 1 & 0 & 0 \\
0 & -0.0294 & 0.068 & 0 \\
0 & 0 & 0 & 1 \\
0 & 0.00173 & 0.96 & 0
\end{array}\right]\left[\begin{array}{l}
\theta_{1} \\
\dot{\theta}_{1} \\
\theta_{2} \\
\dot{\theta}_{1}
\end{array}\right]+\left[\begin{array}{c}
0 \\
0.175 \\
0 \\
-0,01
\end{array}\right]
$$

\section{Hasil \& Pembahasan}

\section{A. Keterkontrolan}

Diberikan sistem linear invariant waktu yang disajikan oleh persamaan:

$\left\{\begin{array}{l}\dot{x}(t)=A x(t)+B u(t) \\ y(t)=C x(t)+D u(t)\end{array}\right.$ 
Jurnal INTENSIF, Vol.1, No.1, Februari 2017

ISSN: 2549-6824

Dari matriks sebelumnya dapat dicari apakah suatu sistem dapat dikontrol atau tidak, yaitu dengan memperhatikan.

$A=\left[\begin{array}{cccc}0 & 1 & 0 & 0 \\ 0 & -0.0294 & 0.068 & 0 \\ 0 & 0 & 0 & 1 \\ 0 & 0.00173 & 0.96 & 0\end{array}\right], B=\left[\begin{array}{c}0 \\ 0.175 \\ 0 \\ -0,01\end{array}\right]$

Dengan memperhitungkan $M_{c}=\left(B|A B| A^{2} B \mid A^{3} B\right)$ maka:

$M_{c}=\left(\begin{array}{cccc}0 & 0.175 & -0.0051 & -0.0005 \\ 0.175 & -0.005 & -0.0005 & 0 \\ 0 & -0.01 & 0.0003 & 0.0096 \\ -0,01 & 0.0003 & 0.0096 & -0.0003\end{array}\right)$

Dikarenakan rank $=$ dimensi $=4$ maka matriks tersebut terkontrol.

\section{B. Keteramatan}

Dari sistem sebelumnya akan dicari apakah sistem dapat diamati atau tidak, yaitu dengan memperhatikan.

$A=\left[\begin{array}{cccc}0 & 1 & 0 & 0 \\ 0 & -0.0294 & 0.068 & 0 \\ 0 & 0 & 0 & 1 \\ 0 & 0.00173 & 0.96 & 0\end{array}\right], C=\left[\begin{array}{llll}1 & 0 & 1 & 0\end{array}\right]$

Sehingga

$M_{\circ}=\left(\begin{array}{c}C \\ -- \\ C A \\ -- \\ C^{2} A \\ -\frac{a}{-}\end{array}\right)=\left(\begin{array}{cccc}1 & 0 & 1 & 0 \\ 0 & 1 & 0 & 1 \\ 0 & -0.0273 & -0.892 & 0 \\ 0 & 0.0008 & -0.0019 & -0.892\end{array}\right)$

Dikarenakan rank $=$ dimensi $=4$ maka sistem dapat teramati.

\section{Bentuk Kompanion Terkontrol}

Pada bagian ini dibahas suatu bentuk yang dinamakan bentuk "'kompanion". Bentuk kompanion ini bermanfaat terutama untuk masalah penempatan pole-pole yang sesuai diinginkan sehingga sistem loop-tutup "terstabilkan". Bentuk awal:

$\left\{\begin{array}{l}\dot{x}(t)=A x(t)+B u(t) \\ y(t)=C x(t)+D u(t)\end{array}\right.$

Kemudian ditransformasi menjadi:

$\left\{\begin{array}{c}\dot{x}(t)=\bar{A} \bar{x}(t)+\bar{B} u(t) \\ y(t)=\bar{C} \bar{x}(t)\end{array}\right.$

Dengan mengubah matriks awal menjadi bentuk transformasi maka didapatkan matriks baru sebagai berikut. 


$$
\begin{aligned}
& \bar{A}=\left(\begin{array}{cccc}
0 & 1 & 0 & 0 \\
0 & 0 & 1 & 0 \\
0 & 0 & 0 & 1 \\
-1 & -0.03 & 0 & 0
\end{array}\right), \bar{B}=\left(\begin{array}{l}
0 \\
0 \\
0 \\
1
\end{array}\right) \\
& \text { Kemudian untuk mencari matriks } \bar{C} \text { dengan cara } \\
& \bar{c}=C Q \\
& Q=R \bar{R}^{-1}=M_{c} \bar{M}_{c}^{-1} \\
& M_{c}=\left(\begin{array}{cccc}
0 & 0.175 & -0.0051 & -0.0005 \\
0.175 & -0.005 & -0.0005 & 0 \\
0 & -0.01 & 0.0003 & 0.0096 \\
-0,01 & 0.0003 & 0.0096 & -0.0003
\end{array}\right) \\
& \bar{M}_{c}=\left(\begin{array}{cccc}
0 & 0 & 0 & 1 \\
0 & 0 & 1 & 0 \\
0 & 1 & 0 & 0 \\
1 & 0 & 0 & -0.3
\end{array}\right), \bar{M}_{c}^{-1}=\left(\begin{array}{cccc}
0.3 & 0 & 0 & 1 \\
0 & 0 & 1 & 0 \\
0 & 1 & 0 & 0 \\
1 & 0 & 0 & 0
\end{array}\right) \\
& \text { didapatkan : } \\
& Q=\left(\begin{array}{cccc}
-0.005 & -0.0051 & 0.175 & 0 \\
0.0525 & -0.0005 & -0.005 & 0.175 \\
0.0096 & 0.0003 & -0.01 & 0 \\
-0,0033 & 0.0096 & 0.0003 & -0.01
\end{array}\right) \\
& \text { Sehingga didapatkan } \bar{C} \\
& \bar{C}=\left(\begin{array}{llll}
0.0091 & -0.0048 & 0.165 & 0
\end{array}\right)
\end{aligned}
$$

Dengan mengingat bentuk transformasi kompanion terkontrol adalah sbb

$$
\left\{\begin{array}{c}
\dot{x}(t)=\bar{A} \bar{x}(t)+\bar{B} u(t) \\
y(t)=\bar{C} \bar{x}(t)
\end{array}\right.
$$

Maka didapatkan bentuk kompanion terkontrol:

$$
\begin{aligned}
\dot{\bar{x}}(t) & =\left(\begin{array}{cccc}
0 & 1 & 0 & 0 \\
0 & 0 & 1 & 0 \\
0 & 0 & 0 & 1 \\
-1 & -0.03 & 0 & 0
\end{array}\right) \bar{x}(t)+\left(\begin{array}{l}
0 \\
0 \\
0 \\
1
\end{array}\right) u(t) \\
y(t) & =\left(\begin{array}{llll}
0.0091 & -0.0048 & 0.165 & 0
\end{array}\right) x(t)
\end{aligned}
$$

D. Bentuk Kompanion Teramati

Bentuk awal:

$$
\begin{gathered}
\left\{\begin{array}{c}
\dot{x}(t)=A x(t)+B u(t) \\
y(t)=C x(t)+D u(t)
\end{array}\right. \\
\left\{\begin{array}{c}
\dot{x}(t)=A^{T} x(t)+C^{T} u(t) \\
y(t)=B^{T} x(t)
\end{array}\right.
\end{gathered}
$$

Bentuk transformasi:

Dengan mengubah matriks awal menjadi matriks transformasi maka didapatkan matriks kompanion teramati: 


$$
\begin{aligned}
\dot{x}(t)=\left(\begin{array}{cccc}
0 & 0 & 0 & -1 \\
1 & 0 & 0 & -0.03 \\
0 & 1 & 0 & 0 \\
0 & 0 & 1 & 0
\end{array}\right) x(t)+\left(\begin{array}{c}
0.0091 \\
-0.0048 \\
0.165 \\
0
\end{array}\right) u(t) \\
y(t)=\left(\begin{array}{llll}
0 & 0 & 0 & 1
\end{array}\right) x(t)
\end{aligned}
$$

\section{E. Kestabilan}

Sebelumnya harus dapat dicari nilai eigen dari suatu sistem pada persamaan (30) tersebut. Dengan cara $(A-\lambda I) v_{1}=0$

$A=\left[\begin{array}{cccc}-\lambda & 1 & 0 & 0 \\ 0 & -0.0294-\lambda & 0.068 & 0 \\ 0 & 0 & -\lambda & 1 \\ 0 & 0.00173 & 0.96 & -\lambda\end{array}\right]$

Dari persamaan matriks didapat nilai eigen: $\lambda_{1}=0, \lambda_{2}=-18.09, \lambda_{3}=7.11, \lambda_{4}=-5.644$

Dari teorema yang telah dijelaskan diatas, dapat dilihat bahwa sistem tersebut merupakan sistem yang tak stabil pelana.

\section{KeSIMPUlan \& SARAN}

Dari perhitungan yang telah dilakukan diatas, maka dapat ditarik kesimpulan bahwa sistem dari pendulum terbalik adalah sistem yang dapat dikontrol dan dapat diamati. Selain itu sistem juga dapat dibentuk menjadi sistem berbentuk kompanion terkontrol dan bentuk kompanion teramati. Sistem pendulum terbalik merupakan sistem yang tidak stabil pelana. Untuk penelitian selanjutnya diharapkan dapat mengubah sistem yang tidak stabil pelana menjadi sistem yang stabil serta dapat dikontrol untuk mendapatkan solusi paling maksimum.

\section{DAFTAR Pustaka}

[1] Subiono, (2013). "Sistem Linear dan Kontrol Optimal", Jurusan Matematika Institut Teknologi Sepuluh Nopember, Surabaya.

[2] Shailaja Kurode, a. C. (2011). Swing-Up and Stabilization of Rotary Inverted Pendulum using Sliding Modes. 10685-10690. 